\title{
Kantian Essentialism in the Metaphysical Foundations
}

\author{
Lydia Patton*
}

\begin{abstract}
Ott (2009) identifies two kinds of philosophical theories about laws: top-down, and bottom-up. An influential top-down reading, exemplified by Ernst Cassirer, emphasized the 'mere form of law'. Recent bottom-up accounts emphasize the mind-independent natures of objects as the basis of laws of nature. Stang and Pollok in turn focus on the transcendental idealist elements of Kant's theory of matter, which leads to the question: is the essence of Kantian matter that it obeys the form of law? I argue that Kant has an independent theory of matter in the Metaphysical Foundations of Natural Science, one that gives what Kant himself calls a "real definition" of matter as a theoryindependent (if not mind-independent) entity. I argue that this matter theory underpins physical arguments about inertia and impenetrability which resemble Einstein's arguments about the unification of fields in general relativity.
\end{abstract}

Just give me matter, and I will build you a world from it.

Immanuel Kant, Universal Natural History and Theory of the Heavens, 1755

Walter Ott (2009, introduction) identifies two kinds of philosophical theories about laws: top-down, and bottom-up. ${ }^{1}$ Top-down law theorists, like Descartes, argue that the laws govern the course of nature. Even if the objects, bodies, or substances that instantiate the laws vary, the laws themselves are invariant-they are commands. Bottom-up law theorists, like Locke, argue that the properties, natures, or essences of objects or substances ground the laws and their reach. In the past, few readers of Kant defended a view according to which Kant has what Ott calls a 'bottom-up' account of the laws of nature, and of the laws of physics in particular.

An influential top-down reading by the Marburg School of neo-Kantianism, exemplified by Ernst Cassirer and Hermann Cohen, emphasized the "mere form of law" and the "validity" of the a priori laws (or principles) for a given domain (see, e.g., Patton [2009]). The relevant dynamical properties of material substances were determined by the a priori laws, not vice versa. Messina (2017) calls this and allied 
top-down views the "Derivation Account (DA)." Michael Friedman often is identified as an exponent of the Marburg reading. ${ }^{2}$

Messina (2017) and Breitenbach (forthcoming) delineate a number of bottom-up responses to the DA, including the Necessitation Account (NA) found in work by Watkins (2005), Kreines (2009), and Messina himself. ${ }^{3}$ On this view, the command of a priori law is grounded in the natures of mind-independent substances and their interactions. Thus, as Kreines (2009) notes, on the Necessitarian Account our knowledge of the ultimate basis of Kantian laws may be limited.

It may be correct that if the natures of mind-independent objects ground the laws, then Kant must concede that we can't know that ground. However, much depends on how we define the 'natures' or 'essences' of objects. Stang (2016) and Pollok (2001) have emphasized the role of transcendental idealism in Kant's argument in the Metaphysical Foundations of Natural Science (MFNS). As Stang (2016) argues, it is the "essence" of matter to be an object of experience, on Kant's account. Since the MFNS lays out the essential properties of matter and of material bodies, those properties must be of matter as an observable. Pollok (2001) argues, as well, for a reading of the MFNS that emphasizes transcendental idealism.

In what follows, I will argue for a reading of Kant's MFNS according to which the laws that feature in the Dynamics, the Mechanics, and the Phenomenology are fundamentally bottom-up, consistent with the NA, but in the sense that they support possible determinations of matter as it can be an object of experience. On the reading that follows, the laws are valid for bodies with certain essential properties: bodies whose concepts can be given a "real definition," as Kant puts it in the Jäsche Logik (9:143f.). In the MFNS Kant lays out the fundamental properties of material bodies, and he gives real definitions of mass, matter, material substance, and material body in that work. Kantian laws, as necessary, universal a priori commands, do not apply with necessity to any objects of a possible experience, independently of their constitution. The necessity and universality of the laws of physics depend on the constitution and real definition of observable material bodies. ${ }^{5}$

Section 1 discusses the Marburg reading of Kant associated with Friedman and Cassirer, and argues that that reading should not go so far as to suggest that Kant's metaphysics of nature is limited to deriving the a priori consequences of the mere form of law. Section 2 takes up this question, arguing that Kant's metaphysical arguments about material bodies, the fundamental forces with which they are endowed, and the forces of interaction between them go beyond his project in the Critique of Pure Reason of describing properties of objects as they can be perceived. Instead, Kant defends an account of the essential properties of material bodies, and gives a physical argument about the forces with which such bodies can be endowed. Section 3 demonstrates that such an account reinforces Kant's claims that the laws of nature apply universally to material bodies. Such a theory of matter can support Kant's claims that extension and impenetrability are fundamental properties of matter, but that inertia is not.

One might argue that the Kantian reasoning I've described as 'physical' consists merely of a priori or counterfactual claims: if material bodies were to have certain properties, then we could draw certain conclusions about forces of, or interactions 
between, material bodies. Section 4 takes up the question of whether Kant's arguments in the MFNS are genuinely physical arguments. Appealing to recent scholarship by Dennis Lehmkuhl on Einstein's theory of general relativity, the section begins with Einstein's arguments for the unification of inertia and gravity in general relativity. One could argue that Einstein's arguments are counterfactual as well: if we assume a certain structure in GR (the geodesic equation), then one can draw certain conclusions about the unity of inertial and gravitational forces. But Einstein's reasoning is robustly physical: it is about the physical consequences of our acceptance of a theory. It is about how we decide about which fundamental forces exist, or do not exist, based on the simplest expression of a background formal theory. ${ }^{6}$ Mutatis mutandis, Kant's theory of matter in the MFNS takes this form. Thus, I conclude that we can attribute a genuine matter theory to Kant, a theory with recognizable physical consequences.

\section{THE DERIVATION ACCOUNT OF THE LAWS OF PHYSICS}

In Einstein's Theory of Relativity, Ernst Cassirer traces a discussion of the laws of mechanics in Newton and Euler, who thought that the laws of mechanics were universal and necessary, and that the certainty of those laws has implications for our commitments about bodies. In the meantime, Cassirer points out, the "mechanical" worldview was replaced by the "electro-dynamical" one, and the implications of the laws of mechanics for the metaphysics of body came to seem increasingly local (Cassirer 1953, 353). In response, as Cassirer goes on to argue, "above all it is the general form of natural law which we have to recognize as the real invariant and thus as the real logical framework of nature in general" (Cassirer 1953, 375). Cassirer sees himself as inspired by Kant in isolating the "form of natural law" from local conditions.

On the Marburg reading, often identified with Cassirer and with Michael Friedman, the 'form' of the laws of nature is required to establish the ontological consequences of those laws within the system of nature. The laws can have ontological or physical consequences, but those consequences must be local. Nonetheless, we can argue that the fundamental properties of matter, including the dynamical relationships into which material bodies can enter, may depend constitutively on the kind of law-governed properties we must ascribe to matter a priori. For instance, we are able to make certain categorical determinations of matter a priori to support the revised version of Newton's "deduction" of the law of gravitation "from the phenomena" that Kant provides in the fourth, "Phenomenology" chapter of the MFNS. On Friedman's reading, this chapter explains

how attributions of motion and rest to matter can be successively determined under the modal categories of possibility, actuality, and necessity - thereby resulting in a distinction between "true" and merely "apparent" motion. Kant ... here develops a reconstruction of Newton's "deduction from the phenomena" of the law of universal gravitation in Book 3 of the Principia. (Friedman 2014, $535)$ 
Friedman identifies three steps in this deduction, paraphrased below:

1. The observable phenomena are Kant's starting point: "the moon relative to the earth, the moons of Jupiter and Saturn relative to the planets in question, and the planets relative to the sun." These are "merely relative motions," which are at this stage only possible (Friedman 2014, 535).

2. Next, using the law of inertia, Kant derives centripetal, inverse-square accelerations of satellites towards their primary bodies (e.g., "the moon towards the earth"). These "true ... orbital rotations ... now count as actual" (Friedman 2014, 536).

3. Finally, Kant shows that these accelerations are "proportional to the quantities of matter of the corresponding primary bodies" and that they are "also everywhere mutual between any two gravitationally interacting bodies." This allows Kant to argue, on the basis of the law of the equality of action and reaction, that any two gravitationally interacting bodies accelerate in opposite directions and "in inverse proportion to their masses" (Friedman 2014, 536).

The three stages of the deduction from the phenomena correspond to the Postulates of Empirical Thought: possibility, actuality, and necessity. Friedman concludes that "In thus determining all the relevant motions in question as first possible, then actual, and finally necessary we have, by the same argument, also established the law of universal gravitation." Moreover,

since each of these mutual accelerations has just been determined as necessary in accordance with the Postulates of Empirical Thought, the law of universal gravitation has itself been determined as necessary in the same sense-relative, that is, to the initial Keplerian Phenomena from which we began." (Friedman 2014, 536, emphasis added)

Friedman's reading relativizes the Kantian a priori to the Keplerian phenomena: the laws are necessary to determining the observed motions as necessary. But to which aspects of those phenomena are the laws relative? To the apparent motions of the bodies? Or to the essential qualities of the bodies in motion? Or to both?

One way of reading the procedure outlined here rests on a classic top-down account of Kantian laws. We begin with observable phenomena, but end by 'determining all the relevant motions' a priori. That determination is independent of the physical properties of any given set of material bodies, and applies to bodies in general. We isolate the mutual accelerations, speeds, changes of the state of motion that the observed phenomena exemplify, and then determine these motions 'as necessary in accordance with the Postulates of Empirical Thought', which are themselves pure and general rules for the synthesis of representations. Thus, we can prove that the laws are universal, precisely because we can prove that they are necessary. That any possible bodies whatsoever must move in the way prescribed follows from the generality of the proof.

A number of objections can be made to a purely deductivist account of the MFNS. It cannot be the case that from a pure determination of motion alone, for 
Kant, we establish a universal law a priori about the motion of objects. As Kant's infamous footnote makes clear, there can be no pure, a priori science of the motion and movability of objects:

Motion of an object in space does not belong in a pure science and thus not in geometry. For, that something is movable cannot be cognized a priori but only through experience. But motion, as the describing of a space, is a pure act of synthesis of the manifold in outer intuition in general through the productive imagination and it belongs not only to geometry, but even to transcendental philosophy. (B155n)

It could be replied that the deduction from the phenomena shows that the laws of 'motion, as the describing of a space' govern the motion of objects in space. But this is unlikely to be the case, for Kant, without the essential basis of an account of substance as the movable in space, provided in the Dynamics section of the MFNS. The experience and especially the quantitative determination of motion, for Kant, always requires a self-subsisting substance that underlies that motion. Otherwise, how are we to establish that the quantity of motion we attribute to the object is not an artefact of the subject's motion with respect to the object, or with respect to other objects? Kant is preoccupied with precisely this question in the Phoronomy and Dynamics sections of the MFNS.

The Marburg reading can be criticized on the grounds that it appears to begin with the phenomena, and move to a bony level of abstraction, in which motion is detached from bodies to form a dynamical exoskeleton. The laws of nature then are attributed to possible motions, considered in isolation from the bodies or the matter that is in motion. The universal necessity of the laws of nature is then derived from the fact that the necessity of the law of gravitation, for instance, does not depend on any property of bodies, only on the quantitative, dynamical relationships determined by the mutual motions of the bodies in question, considered in abstraction from the bodies themselves and from the matter that constitutes them. On such a top-down reading, Kant's laws of motion govern the behavior of matter, and thus of material objects. The 'Keplerian phenomena' can be read as spatiotemporally distributed properties, and the mechanical or dynamical relations that vary proportionally to the distribution of matter do not depend on any particular such distribution. This is a possible account of why Kantian laws of nature are universal and necessary. It is also the sense in which the laws describe 'transcendental' relationships.

But such an account would not explain why Kant's four chapters in the MFNS give successively more precise definitions of matter and of material substances. Moreover, it would not explain why Kant appears to think that his Dynamics chapter, for instance, can support an account of the fundamental forces that it is legitimate to ascribe to material bodies.

\section{TRANSCENDENTAL IDEALISM AND REAL DEFINITION}

One response to such criticisms might be to argue that matter, in the MFNS, is defined by its observability. Stang argues that part of the real essence of matter is given, 
for Kant, by its being an object of a possible experience (Stang 2016, \$8.3). The "crucial claim" of transcendental idealism is that "the a priori conditions of a possible experience in general are at the same time conditions of the possibility of the objects of experience" (A111). In \$7.3, Stang argues that "conformity to the forms of experience is part of what makes [any possible object of experience] $\mathrm{x}$ a possible object of experience," and thus "being an object of possible experience, and hence conforming to the forms of experience, is part of the essence of matter" (Stang 2016, 252f.).

Stang emphasizes that matter is an object of possible experience, and thus that its essence is determined not just by the laws to which it is subject, but by the conditions for conformity to the "forms of experience" (Stang 2016, 253). On this reading, the laws of material bodies are the laws of observable bodies. The transcendental idealist reading thus can address the objections to the Derivation Account cited above.

The advantages of a transcendental idealist reading of Kant should need little explanation. However, a reading that emphasizes the transcendental idealist elements of the definition of matter in the MFNS, without further elaboration, risks falling into a trap. We might argue that "being an object of possible experience, and hence conforming to the forms of experience, is part of the essence of matter," and then that physical bodies are material bodies (Stang 2016, 253). Or we might say, as Hyder glosses Pollok's (2001) view, that attractive and repulsive forces in the Dynamics chapter are "necessary categorical determinations of the empirical concept of matter just because they are prerequisites for matter's being a possible percept" (Hyder 2003, 421).

It seems a small step to say that the esse of matter is percipi. The old criticism of Kant, that he is a Berkeleian idealist despite his best intentions, seems a possible consequence of reading the MFNS in this way. If the fundamental forces in the Dynamics chapter, the gravitational force in the Phenomenology chapter, and the like are all determinations of matter only as something that can be perceived, then Kant would need to give a further argument to show that the forces in the Dynamics and the Phenomenology are physical forces attributable to material bodies.

That pitfall is removed, however, if we construct a deliberately bottom-up reading of Kant's MFNS. To do so, we can say even more about what Kant sees as the essence of matter. The categories and the principles are the laws of the understanding, the rules that determine the form of the course of experience. But the categories are also the rules for determining the properties of substances (see, e.g., Friedman 2004, $\mathrm{xx}-\mathrm{xxi} ;$ MFNS 4:551). In the context of the MFNS, Kant gives an account of what properties material substances and bodies must have to support the laws of mechanics.

In particular, Kant appeals to the "real definitions" of material bodies ${ }^{7}$ as a basis for his arguments that impenetrability and extension are fundamental properties of matter, but that inertia is not. ${ }^{8}$ In the final sections of the Jäsche Logik, Kant identifies "real definitions" as those that give characteristics ("Merkmale") that define the real essences of things, in Kant's own sense-a list of properties that, if an object were to lose any one of them, that object would cease to be what it is $(9: 143)$.

Here, we can return to the final stage of the deduction from the phenomena. In that stage, we must be able to determine that "the accelerations [of the satellites] in 
question are directly proportional to the quantities of matter of the corresponding primary bodies ... and that such accelerations are also everywhere mutual between any two gravitationally interacting bodies" (Friedman 2014, 536). It may seem that this requires only that we determine the absolute quantities of matter and of mutual acceleration, since we are showing that acceleration is proportional to the quantity of matter. But note that this proportion is shown to be well defined with respect to "the quantities of matter of the corresponding primary bodies" and that the accelerations are shown to be "mutual between any two gravitationally interacting bodies" (ibid.).

To be able to determine these proportions, note what, by Kant's own lights, we must be able to do:

1. Determine that two bodies actually are moving, and accelerating, with respect to each other, which requires distinguishing true from apparent motions, and motion from acceleration.

2. Determine the quantities of matter of any two bodies on a scale that allows us to compare those quantities to each other and to ascribe them to the bodies (on an objective scale).

3. Show that, for any two 'gravitationally interacting bodies', we can measure their mutual acceleration, and it will have the proportions defined in (1) and (2).

It is integral to the deduction from the phenomena that we show that mutual acceleration is essential to determining two bodies as gravitationally interacting. We must be able to show that if two bodies are not accelerating with respect to each other in a way that is proportional to their mass, those bodies are not interacting gravitationally. This is a real definition, founded on a law of interaction. But that real definition is not based only on a pure, a priori law. It is based also on our ability to determine the quantitative properties of the 'primary bodies' that are being defined as interacting. Only with a first-order definition of those properties can we formulate the laws as Kant does in the MFNS.

It is possible to find a univocal value for the mutual acceleration of any bodies proportional to their quantities of matter, as is done in Newton's Principia and in turn in the MFNS. For Kant, this possibility is based on our ability to determine the quantity of matter and of motion for any two bodies. That, in turn, requires that the concepts of matter and motion be part of the real definition of bodies with respect to the system of nature. If the quantity of matter of a body cannot be univocally established, and if the true motions of that body cannot be described with respect to other material bodies, then it is not a 'material body' in the sense necessary to construct a system of nature.

Systematic knowledge (Wissenschaft) is "a whole of knowledge as a system and not as an aggregate" (Jäsche Logik, 9:139). This, in turn, requires real definitions of the elements of the system of knowledge, as Kant goes on to say in the Logik. Only if we can define the essential qualities of material bodies (perhaps including movability, impenetrability, and extension) can we construct a system on the basis of the laws of 
interaction of material bodies that can be observed. The laws are not laws of motion generally, but rather of the motions (Phoronomy chapter), forces (Dynamics chapter), and interactions (Mechanics chapter) of material bodies.

\section{REAL ESSENCES AND LAWS OF NATURE}

Kantian laws of mechanics and of dynamics are universal because they apply to all material bodies, and the essence of these bodies can be defined, as in the MFNS. In the context of the MFNS, a "body" is a material substance with a certain form (4:537). The Phenomenology chapter requires the groundwork of the first three chapters, in which Kant provides a conceptual framework for describing the essential properties of matter and of material bodies when determining the laws of nature in the context of natural philosophy, including laws of gravitation, cohesion, and elasticity of bodies. For these laws to be determined as necessary a priori relative to the phenomena, matter must be endowed with a fundamental force of repulsion, and with fundamental properties of impenetrability and extension, as I explain in the section following. This type of universality is not absolute, but relative to the essential qualities of material bodies, to the conditions for the possible experience of those bodies, and to the necessity of the essential qualities listed to the deduction from the phenomena provided in the Phenomenology.

Is there reason to believe Kant held to this type of universality? There is a clear precedent, namely Newton's Rule III for reasoning in philosophy, in the Principia: "Those qualities of bodies that cannot be intended and remitted and that belong to all bodies on which experiments can be made should be taken as qualities of all bodies universally" (Newton 2014/1687, 795). The key difference, of course, is that Kant's account of the 'real essences' of bodies cannot be based on observation and experiment. But we can define the 'real essence' of matter and of material bodies a priori. And, in so doing, we can derive the laws that material bodies must obey to be objects of a possible experience, and we can also determine the properties they must have in order to be a part of a system of nature.

The step in Kant's argument that may be forgotten is the appeal, inspired by Euler, to the metaphysical properties of bodies. ${ }^{9}$ Kant does not think that the laws of physics govern independently of the properties of material bodies. The laws of physics are universal and necessary because they are derived from the principles of possible experience and knowledge of material bodies. However, Kant does not ground his essentialism in a commitment to empirical natural kinds. 'Body', 'substance', and the like can be given real definitions precisely because they are not empirical concepts, and are not derived from the phenomena. Rather, we construct a definition of what a body must be in order to play its role in the system of natural science.

As we know from the Critique, for a substance to be an object of possible experience, our representations of it must be synthesized not only according to the categories of relation, but also according to the categories of quantity and quality. According to the Principles, this in turn means that our observations (intuitions) of these bodies must be extensive magnitudes composed successively in time, and must be intensive magnitudes that possess a degree. In the MFNS, all these are desiderata 
on what counts as a 'material substance' or 'body' that can take its place as part of the system of natural science.

Kant's account of the laws of nature has been read as a rejection of Newton's and Euler's view that the laws are founded in the metaphysics of body. But what properties of body and of matter must be asserted to derive the a priori relationships in Kant's deduction from the phenomena? Kant maintained that establishing a system of nature requires determining the real essences of the system's elements. In the MFNS, giving real definitions of matter, material substance, and material body is necessary to deducing the laws of nature. There, Kant argues for impenetrability and extension as fundamental properties of matter, and that inertia is not a fundamental property, which supports a bottom-up reading of Kant on the laws of nature.

Stan (2013) criticizes the "Marburg reading" of Kant, exemplified by Friedman's work, on the ground that Kant is motivated not by the desire to "derive Newton's laws," but by deeper problems in the Leibnizian tradition. I agree that we must look beyond Newton to find the motivation for Kant's arguments in the MFNS. ${ }^{10}$ A much earlier attempt to do that is found in Timerding's "Kant und Euler," which details problems in mechanics in the Leibniz-Wolff tradition, on the one hand, and the Cartesian tradition, on the other; their reception by Euler and Baumgarten; and the influence of the latter on Kant.

Another source for the structure of Kant's account in the MFNS is Euler's "Recherches sur l'origine des forces." 11 As DiSalle notes, "it is well known" that Kant “regarded Euler's critique of Leibnizian metaphysics, and his defense of Newtonian space and time, as a crucial influence on his own developing conceptions, not only of space and time in particular, but of the relation between physics and metaphysics in general" (DiSalle 2013, 454). Kant admired elements of Euler's work ${ }^{12}$ "Réflexions sur l'espace et le temps," in which Euler writes that the basic laws of mechanics "absolutely must be founded in the nature of body; and since it is metaphysics that concerns itself with the nature and properties of bodies, the knowledge of these truths can serve as a guide to its thorny researches" (Euler 1748, 324-25, trans. DiSalle 2013, 454).

Nonetheless, Harman is skeptical of the claim that Kant was influenced by Euler's work, arguing that "Kant does not . . . accept the Newton-Euler doctrine that 'inertia' and 'impenetrability' were 'essential' properties of matter" (Harman 1983, 240). ${ }^{13}$ Harman is correct that Kant did not argue for inertia as a fundamental property of matter. As Kant puts it, to use the word "inertia" to describe matter means "nothing other than its lifelessness as matter in itself ... all matter in itself is lifeless. The law of inertia says that and nothing else" (MFNS 4:544). ${ }^{14}$

But Kant does argue for impenetrability as a fundamental property of matter, explicitly, and at some length. In the MFNS, in the "Erklärungen" of the laws of mechanics and of dynamics, Kant defines matter, material substance, mass, and body:

Material substance is that in space, which is movable for itself, that is, distinguished from all others that exist outside it in space. The movement of a part of matter, through which it ceases to be a part, is separation. Separation of the parts of matter is physical division. (MFNS 4:502f.) 
The quantity of matter is the amount of the movable in a particular space. The same, insofar as all its parts in its motion can be regarded as active (moving) simultaneously, is called mass, and one says, a matter acts in mass, if all its parts move in the same direction, without exercising its moving force at the same time. A mass of a particular form is called a body (in the mechanical sense). (MFNS 4:537)

These characteristics constitute real definitions of matter and of material substance. In the Jäsche Logik, Kant talks of "Sach-Erklärungen oder Real-Definitionen" (9:143). These are those explanations or definitions "that suffice for knowledge of the object, of its internal determinations, insofar as they explain the possibility of the object from its internal characteristics [Merkmale]." The real definition of matter itself is effected through the four "Erklärungen" provided for the four sections, the metaphysical foundations of phoronomy (kinematics), dynamics, mechanics, and phenomenology:

Phoronomy. "Matter is the movable in space." (MFNS 4:480)

Dynamics. "Matter is the movable, insofar as it fills a space. To fill a space means to resist any movable, which attempts to penetrate a certain space through its movement. A space that is not filled is an empty space." (MFNS 4:496, emphasis added)

Mechanics. "Matter is the movable, insofar as it has motive force in itself." (MFNS 4:536)

Phenomenology. "Matter is the movable, insofar as it as such can be an object of experience.” (MFNS 4:554)

Matter is movable, impenetrable, has motive force proper to itself, and can be the object of experience. This is not a list of accidental properties of matter: the 'is' here is a collective 'is' of identity, not of predication. Matter just is that which is movable, impenetrable, has motive force proper to itself, and can be the object of experience. Anything that has these qualities is matter; anything that fails to have any one of them, is not.

Kant's second law of dynamics has it that "Matter fills its spaces through repulsive forces of all its parts, i.e. through a force of extension proper to it, that has a specific degree" (MFNS 4:499). In a remark on this law, Kant says "Impenetrability as a fundamental property [Grundeigenschaft] of matter, through which it first manifests itself to our senses as something real in space, is nothing but the power of extension of matter (Lehrsatz 2)" (MFNS 4:508). Impenetrability and extension, for Kant as for Newton and Euler, are fundamental properties of matter. ${ }^{15}$

In my view, a reading of the MFNS according to which the work gives the "foundations" of science but no scientific argument is mistaken. Among Kant's arguments in the MFNS are physical arguments, not only about the laws of nature, but also about certain fundamental forces we can ascribe to matter.

\section{KANT AND PHYSICAL REASONING}

On a bottom-up reading, the arguments in the Dynamics, in the Mechanics, and in the Phenomenology constitute a real definition of matter, material substance, and 
material body. Moreover, Kant's real definition of matter, and his ascription of fundamental forces to matter, is not merely a conceptual foundation for natural science. It supports real results of natural science, in the sense that we can read Kant as laying out actual physical arguments in the MFNS.

Kant rejects the arguments given by Newton, Euler, Wolff, and others that matter is endowed with a fundamental force of inertia (Stan 2013, \$2; Harman 1983). Kant argues, instead, that matter is entirely passive-lifeless — and that this is the only sense in which we can ascribe "inertia" as a fundamental or essential property of matter. This is, however, only a negative quality - the absence of a force - and so it is not part of the real essence of matter. In the MFNS, Kant dispenses with the postulate of an inertial force, and uses only extension, impenetrability, movability and the other listed properties as the fundamental properties of matter.

Kant's argument bears some resemblance to Einstein's argument about the unification of inertia and gravity in general relativity (GR). According to recent research by Lehmkuhl, Einstein himself saw the structural relationships of general relativity as having consequences for his account of inertia and of gravity. Einstein "saw the geodesic equation as manifesting the unification of inertia and gravity in GR" (Lehmkuhl 2014, 317). Lehmkuhl shows that Einstein thought of this unification as similar to the unification of electric and magnetic fields in special relativity (Lehmkuhl 2014, 323). In writings cited by Lehmkuhl on the development of the theory of relativity, Einstein concludes, "the existence of the electric field is a relative one, depending on the state of motion of the coordinate system used; only the electric and magnetic field together can be attributed a kind of objective reality" (Einstein 2002/1920, 265).

As Lehmkuhl continues, "a result of this unification" of gravity and inertia in GR "is that the existence of gravitational fields (in contrast to gravitational-inertial fields) becomes coordinate-dependent" (Lehmkuhl 2014, 323). Just as electric fields become coordinate-dependent in SR, while the electro-magnetic field is "objectively" real, in GR gravitational fields are coordinate-dependent, and gravitational-inertial fields are objectively real. In fact, the unification appears even more profound in GR (Lehmkuhl 2014, 325).

Einstein argues that the geodesic equation applies to gravitational fields, but that such fields need be posited only when comparing general relativity to special relativity, or to the Newtonian theory. Really, the equation requires the existence of only one field, the gravitational-inertial field. Einstein appeals to the geodesic equation in the unification of gravitational and inertial fields, just as the principle of relativity (that the laws of electrodynamics and optics hold in all reference frames) is the source of the mixing of electric and magnetic fields. Einstein's argument depends on the use of the geodesic equation, or of the principle of relativity, to argue that a particular theoretical postulate is unnecessary. In the case of SR, it is the coordinateindependent existence of the electric field; in the case of GR, it is the coordinateindependent existence of the gravitational field.

Einstein argues that GR does not require the independent existence of a gravitational field. Kant argues that his laws of mechanics do not require that matter be endowed with an inertial force. Thus, a possible (neo-)Kantian reading of general 
relativity would appeal to Euler's assertion that the laws of physics are "absolutely" founded on the nature of the bodies (or fields) that they describe. In practice, Kant adds to Euler's assertion that, if a particular property or quality of matter, bodies, or fields, such as inertia, is not part of the definition of those bodies as described by mechanics, then we need not include that force in our accounting of the constitution of bodies or of the laws of nature themselves.

A thoroughgoing reading of the theory of relativity, according to this Kantian essentialist view, would establish the "real definitions" of the gravitational, inertial, electric, and magnetic fields relative to the laws of physics, thus expanding Kant's theory of material bodies and their interactions into a theory of the ontological interpretation of the relativistic equations, founded in the properties we must ascribe to the fields in order to give them a real definition.

\section{CONCLUDING REMARKS}

The view of Cassirer that Kant focuses on the mere 'form of law' in the MFNS has been eroded away recently. A more robust landscape of Kantian natural science includes an account, from the Necessitarian camp, of the 'natures' of bodies as the foundation for the laws of nature.

That account, as Kreines (2009) notes, makes the laws of nature unknowable. The transcendental idealist reading of Stang and Pollok repairs this lack, but at the risk of making Kant indiscernible from a Berkeleian idealist, who argues that the essence of matter is to be perceived.

Kant himself has a clear account of the 'essence' of matter, namely, his 'real definition' of matter, material substance, and material body in the MFNS. That definition is given in the four chapters of the MFNS. In the final three chapters, Kant provides a theory of matter that is the basis of physical arguments, including arguments against inertia and for impenetrability as fundamental forces of matter. These arguments are strikingly similar to Einstein's arguments about the consequences of the relativistic equations in GR for the unification of inertia and gravity. Thus, we are forced to say either that Kant has real physical arguments in MFNS, or that Einstein's reasoning about fields in GR is not a real physical argument.

If Kant's matter theory is the basis for real physical consequences, then the hazard of the transcendental idealist reading - that it slides into Berkeleian idealism-is avoided. But this result is achieved only by giving a more substantial account of matter than just that it is subject to the laws of nature or the principles of determination of substances in general, as would be a consequence of the top-down view. Instead, we must give an independent theory of matter and of material bodies. Such a theory is not limited to constitution of material substances in accord with the 'form of law', but rather, must ascribe to matter a number of independent properties. In that sense, Kant's theory in the MFNS is essentialist. ${ }^{16}$

\section{NOTES}

1. Massimi (2014) also uses this way of speaking.

2. I find the question of how to classify Friedman's view somewhat more complex, though I examine his account critically below. 
3. Massimi (2017) also defends an account of laws in Kant that retrieves nomological necessity. She argues for a broadly dispositional essentialist account of Kant's view; and spells out the modal resources available to Kant for retrieving nomological necessity in terms of 'grounds'.

4. References to Kant's works are to the volume and page numbers of the Akademie edition (Kant 1900ff.). Translations are my own. An exception is the Critique of Pure Reason to which I refer by citing the original pagination of the A (1781) and B (1787) edition, respectively. Translations are from Kant (1999).

5. Although 'matter' is an empirical concept, it can be given a real definition, according to Kant. Matter is special in this sense: it is one of the few empirical concepts, if not the only one, that can be given a real definition a priori. This may be one reason why Kant famously is skeptical about the possibility of a mathematical foundation for chemistry and biology-their empirical concepts are not definable a priori.

6. Relative, of course, to the observed phenomena. But as Friedman has emphasized, Kant's account in the Phenomenology is equally relative to the observed phenomena (see Section 1, below).

7. These are not quite Lockean real essences, as Walter Ott has emphasized to me, but are related.

8. In addition to Friedman's focus on Newton, recent scholarship has emphasized the importance of Locke (Stang 2016; Dunlop 2009; Carson 2006; Longuenesse 1998) and Leibniz (Stan 2013; DiSalle 2013) to Kant's account of the laws of nature. Locke argued that the possible relations of bodies are founded in their essences, which are the properties objects must have in order to be what they are. The real essence of a body is the set of essential properties of an object, relative to our abstract ideas of that object. Locke writes, "Essence, even in this sense [i.e., real essence], relates to a Sort and supposes a Species," where a species is an abstract idea (Locke 1975/1689, III.vi.6:443). Essences, for Locke, are dependent on the mind and on ideas: "essential, and not essential, relate only to our abstract Ideas, and the name annexed to them" (III.vi.4:441). I am grateful to Walter Ott for guidance on Locke's view here.

9. Though I cannot follow it up here, Kant's discussion of the 'metaphysical' as opposed to the 'geometrical' properties of space is relevant (see, e.g., Patton [2011], especially the references to further work there).

10. It is doubtful that Friedman thinks Kant's only motivation in the Mechanik and Phänomenologie is to derive Newton's three laws of motion.

11. "The leading perspectives of this text are the derivation of certain short-range forces from impenetrability as a basic property of all matter and the reduction of all forces in nature to such short-range forces. On this basis, all natural events appear to be grounded on three elementary principles, extension, inertia, and impenetrability" (Timerding 1919, 27-28)

12. See, for instance, Allison (2015, 44 and passim).

13. 'In the MFNS he conceives 'inertia' as a law of mechanics which implied the passivity of matter, not as an 'essential' or defining property of material substance" (Harman 1983, 240).

14. A significant conclusion in Kant's investigation into the distinction between mind and matter (see Laywine 1993, ch. 2). Stan (2013, \$3) provides plausible evidence for reading Kant's rejection of inertia as an active force not as a rejection of Newton, but as a rejection of "the Leibnizian consensus" and of Wolff's account of inertia in particular.

15. Massimi gives a detailed and nuanced picture of the development of Kant's dynamical theory of matter as endowed with fundamental attractive and repulsive forces in the Physical Monadology (Massimi 2011, 526), traces its development in the Universal Natural History (Massimi 2011, \$2), and explains clearly to what extent Kant's view are a departure from Newton's theory (Massimi 2011, \$2.2, \$3).

16. I am grateful above all to Michela Massimi and Angela Breitenbach for suggesting that I contribute to this issue of The Monist, and for perceptive and illuminating critique of earlier versions. Walter Ott's reactions and suggestions have resulted in material improvements. Colin McLear sent a draft, "Motion and the Affection Argument," which illuminated a number of questions on Kant's theory of matter which illuminated a number of questions on Kant's theory of matter (McLear, forthcoming).

\section{REFERENCES}

Allison, Henry 2015. Kant's Transcendental Deduction, Oxford: Oxford University Press.

Breitenbach, Angela 2017. "Laws in Biology and the Unity of Nature," in Massimi and Breitenbach, eds. $(2017,237-55)$. 
—. Forthcoming. "Laws and Ideal Unity," in Ott and Patton, eds.

Carson, Emily 2006. "Locke and Kant on Mathematical Knowledge," in Carson and Huber, eds. Intuition and the Axiomatic Method, Dordrecht: Springer.

Cassirer, Ernst 1953/1921. Substance and Function and Einstein's Theory of Relativity, trans. W. and M. Swabey, Mineola, NY: Dover.

DiSalle, Robert 2013. "The Transcendental Method from Newton to Kant," Studies in History and Philosophy of Science 44(3): 448-56.

Dunlop, Katherine 2009. “The Unity of Time's Measure': Kant's Reply to Locke,” Philosopher's Imprint 9(4).

Einstein, Albert 2002/1920. "Fundamental Ideas and Methods of the Theory of Relativity, Presented in Their Development," Collected Papers of Albert Einstein, Vol. 7, Princeton: Princeton University Press.

Euler, Leonhard 1748. "Réflexions sur l'espace et le temps," Histoire de l'Academie Royale des sciences et belles lettres 4: 324-33.

Friedman, Michael 2004. "Introduction," in Kant: Metaphysical Foundations of Natural Science, trans and ed. M. Friedman, Cambridge: Cambridge University Press.

—. 2014. "Laws of Nature and Causal Necessity," Kant-Studien 105(4): 531-53.

Harman, Peter 1983. "Force and Inertia," in Shea, ed. (1983, 229-50).

Hyder, David 2003. "Review of Konstantin Pollok, Kants Metaphysische Anfangsgründe der Naturwissenschaft," Journal of the History of Philosophy 41(3): 421-22.

Kant, Immanuel 1900ff. Kants Werke, Berlin: Preußische Akademie der Wissenschaften.

- 1999. Critique of Pure Reason, trans. P. Guyer and A. Wood, Cambridge: Cambridge University Press.

- 2004. Metaphysical Foundations of Natural Science, ed. Michael Friedman, Cambridge: Cambridge University Press.

Kreines, James 2009. "Kant on the Laws of Nature and the Limitation of our Knowledge," European Journal of Philosophy 17: 527-58.

Laywine, Alison 1993. Kant's Early Metaphysics and the Origins of the Critical Philosophy. Vol. 3, NAKS Studies in Philosophy, Atascadero: Ridgeview.

Lehmkuhl, Dennis 2014. "Why Einstein Did Not Believe that General Relativity Geometrizes Gravity," Studies in History and Philosophy of Modern Physics 46: 316-26.

Locke, John 1975/1689. An Essay concerning Human Understanding, ed. P.H. Nidditch. Oxford: Oxford University Press.

Longuenesse, Béatrice 1998. Kant and the Capacity to Judge, Princeton: Princeton University Press.

Massimi, Michela 2011. "Kant's Dynamical Theory of Matter in 1755, and Its Debt to Speculative

Newtonian Experimentalism," Studies in History and Philosophy of Science 42: 525-43.

—. 2014. "Prescribing Laws to Nature," Kant-Studien 105(4): 491-508.

- 2017. "Grounds, Modality, and Nomic Necessity in the Critical Kant," in Massimi and Breitenbach, eds. (2017, 150-70).

Massimi, Michela and Angela Breitenbach, eds. 2017. Kant and the Laws of Nature, Cambridge:

Cambridge University Press.

McLear, Colin. Forthcoming. "Motion and the Affection Argument," Synthese.

Messina, James 2017. "Kant's Necessitation Account of Laws and the Nature of Natures," in M.

Massimi and A. Breitenbach. eds. (2017: 131-49).

Newton, Isaac 2014/1687. The Principia: Mathematical Principles of Natural Philosophy, trans.

Cohen and Whitman, Berkeley: University of California Press.

Ott, Walter 2009. Causation and Laws of Nature in Early Modern Philosophy, Oxford: Oxford University Press.

Ott, Walter and Lydia Patton, eds. Forthcoming. The Laws of Nature, Oxford: Oxford University Press.

Patton, Lydia 2011. “The Paradox of Infinite Given Magnitude,” Kant-Studien 102(3): 273-89. 
2009. "Signs, Toy Models, and the A Priori," Studies in History and Philosophy of Science 40(3): 281-89.

Pollok, Konstantin 2001. Kants Metaphysische Anfangsgründe der Naturwissenschaft: Ein kritischer Kommentar, Hamburg: Felix Meiner.

Shea, William R., ed. 1983. Nature Mathematized, Dordrecht: Reidel.

Stan, Marius 2013. "Kant's Third Law of Mechanics," Studies in History and Philosophy of Science 44(3): 493-504.

Stang, Nicholas 2016. Kant's Modal Metaphysics, Oxford: Oxford University Press.

Timerding, H.E. 1919. "Kant und Euler," Kant-Studien 23(1-3): 18-64.

Watkins, Eric 2005. Kant and the Metaphysics of Causality, Cambridge: Cambridge University Press. 